\section{AB0936 GOLIMUMAB IMPROVES DISEASE SIGNS AND SYMPTOMS, CONCOMITANT DISEASES AND CONCOMITANT DRUG USE IN PATIENTS WITH PSORIASIS ARTHRITIS IN A REAL-LIFE SETTING IN GERMANY}

K. Krüger ${ }^{1}$, G.R. Burmester ${ }^{2}$, S. Wassenberg ${ }^{3}$, A. Thiele ${ }^{4}$, M.H. Thomas ${ }^{5}$. ${ }^{1}$ Rheumatologisches Praxiszentrum, München; ${ }^{2}$ Department of Rheumatology and Clinical Immunology, Charité- Universitätsmedizin, Berlin; ${ }^{3}$ Rheumazentrum Ratingen, Ratingen; ${ }^{4}$ Krankenhaus St. Josef, Wuppertal, ${ }^{5}$ Medical Affairs, MSD Sharp and Dohme GmbH, Haar, Germany

Background: Golimumab (GLM) has demonstrated efficacy and safety in several randomised clinical trials in Psoriatic Arthritis (PsA) patients. Data on disease signs and symptoms, concomitant diseases and concomitant drug in daily clinical practice are rare

Objectives: The aim of this subanalysis was to assess the effectiveness of GLM in patients with established PsA in a real-world setting in Germany

Methods: Descriptive post-hoc analysis of the non-interventional, prospective, 24 month study GO-NICE. Patients with established PsA starting with GLM $50 \mathrm{mg} \mathrm{SC}$ once monthly under routine clinical care conditions. Endpoint measures were: Physician's Global Assessment (PhGA) of patient's health status (visual analogue scale VAS: 0 no discomfort -10 strong discomfort), change in concomitant diseases, concomitant drug use, inflammatory markers (CRP/ESR), improvement of the skin (PhGA-score: $0=$ none $-3=$ severe).

Results: A total of 501 patients with PsA were included at 121 sites and 231 $(46.1 \%)$ completed the 24 month observation period. At baseline (BL) mean age $50.3( \pm 12.1)$ years, $271(54.1 \%)$ females, mean time since first diagnosis 13.0 \pm 11.5 years, BMI $28.1( \pm 5.4) \mathrm{kg} / \mathrm{m}^{2} .169(73.8 \%)$ patients received basic therapeutics, $286(57.1 \%)$ had none previous biologics use, $136(27.1 \%)$ one, and 79 $(15.8 \%)$ at least two biologics.

439 (87.8\%) had extra-articular diseases manifestations at BL. The most common were psoriasis $(n=394,78.8 \%)$, nail involvement $(n=197,39.4 \%)$, dactylitis $(n=106,21.2 \%)$, and enthesitis $(70,14.0 \%)$ at BL. The three most concomitant diseases were cardiovascular disease $(n=151,30.1 \%)$, depressive disorder $(n=60$, $12.0 \%)$, and diabetes mellitus ( $n=52,10.4 \%)$. On GLM treatment, remarkable improvements were seen (table 1):

\begin{tabular}{|c|c|c|c|}
\hline Measures & $\begin{array}{c}\text { visit 1/ } \\
\mathrm{BL}\end{array}$ & $\begin{array}{c}\text { visit } 5 / \\
\text { month } 12\end{array}$ & $\begin{array}{c}\text { visit 9/ } \\
\text { month } 24\end{array}$ \\
\hline Number of evaluable patients $n(\%)$ & $\begin{array}{c}501 \\
(100)\end{array}$ & $283(56.5)$ & $231(46.1)$ \\
\hline $\begin{array}{l}\text { Physician's Global Assessment (PGA) of patient's } \\
\text { health status }(0-10) \pm S D\end{array}$ & $\begin{array}{c}5.5 \\
( \pm 2.2)\end{array}$ & $2.4( \pm 2.0)$ & $2.1( \pm 2.0)$ \\
\hline \multicolumn{4}{|l|}{ Concomitant diseases } \\
\hline - cardiovascular disease: $\mathrm{n}(\%)$ & $\begin{array}{c}151 \\
(30.1)\end{array}$ & $90(18.0)$ & $74(14.8)$ \\
\hline - depressive disorder: $\mathrm{n}(\%)$ & $\begin{array}{c}60 \\
(12.0)\end{array}$ & $33(6.6)$ & $32(6.4)$ \\
\hline - diabetes mellitus: $n(\%)$ & $\begin{array}{c}52 \\
(10.4)\end{array}$ & $32(6.4)$ & $33(6.6)$ \\
\hline \multicolumn{4}{|l|}{ Concomitant drug use } \\
\hline - MTX: n (\%) & $\begin{array}{c}333 \\
(66.5)\end{array}$ & $135(47.7)$ & $127(55.0)$ \\
\hline · sys. glucocorticoids: n (\%) & $\begin{array}{c}206 \\
(41.1)\end{array}$ & $74(26.1)$ & $48(20.8)$ \\
\hline - NSAIDS/Coxibs: n (\%) & $\begin{array}{c}333 \\
(66.5)\end{array}$ & $173(61.1)$ & $127(55.0)$ \\
\hline \multicolumn{4}{|l|}{ Inflammatory markers } \\
\hline - CRP [mg/l] (\% outside n.r.) & $\begin{array}{c}19.8 \\
(45.8)\end{array}$ & $8.7(16.3)$ & $8.4(15.1)$ \\
\hline - ESR [mm/h] (\% outside n.r.) & $\begin{array}{c}24.9 \\
(36.5)\end{array}$ & $13.7(13.0)$ & $13.6(15.1)$ \\
\hline
\end{tabular}

Additionally, the percentage of patients with severe psoriatic symptoms decreased from $11.8 \%(B L)$ to $1.8 \%$ (M12) to $0.4 \%$ (M24), and the percentage of patient without any symptom increased from $8.8 \%$ (BL) to\% 31.8 (M12) to $36.2 \%$ (M24). An increase in any of the prespecified concomitant diseases was not observed. No new safety signals were detected.

Conclusions: GLM SC once-monthly, administered to PsA patients according to routine clinical practice in Germany, showed remarkable improvements in Physician's Global Assessment of patient's health status, decrease in the number of concomitant diseases and concomitant glucocorticoids use, inflammatory markers (CRP/ESR) and skin symptoms over 24 months of treatment.
Disclosure of Interest: K. Krüger Consultant for: AbbVie, BMS, Celgene, Janssen Biologics, Lilly, MSD, Pfizer, Roche, and Sanofi-Aventis, and UCB, G. Burmester Consultant for: AbbVie, BMS, MSD, Pfizer, Roche, and UCB, S. Wassenberg Consultant for: AbbVie, Chugai, Janssen Biologics, MSD, Novartis, Pfizer, Roche, and UCB, A. Thiele Consultant for: Biogen, Celgene, Chugai, Hexal, Janssen-Cilag, Lilly, MSD, Novartis, Pfizer, UCB, M. Thomas Employee of: MSD Sharp and Dohme GmbH

DOI: 10.1136/annrheumdis-2018-eular.2957

\section{AB0937 EFFICACY OF NEW TREATMENTS ON DACTYLITIS OF PSORIATIC ARTHRITIS: UPDATE OF SYSTEMATIC LITERATURE REVIEW}

M. Sondag, F. Verhoeven, X. Guillot, C. Prati, D. Wendling. Rheumatology, Hopital Jean Minjoz, Besançon, France

Background: Dactylitis is a frequent disabling feature of psoriatic arthritis (PSA) Therapeutic strategy on dactylitis is not really codified.

Objectives: The objective of the study was to evaluate efficacy on dactylitis of differents treatments actually available in PsA.

Methods: We performed a literature review from June 2014 to October 2017 based on Pubmed, using the search terms "psoriatic arthritis" and "treatment" with only clinical trials. 89 articles were identified (English-language reports only). Thus, we selected only randomised, double-blind placebo-controlled trials in which analysis of dactylitis was exposed: 11 articles were selected for full review. Results: Significant improvement of dactylitis $(p<0.05)$ compared to placebo was observed with the use of golimumab in GO-VIBRANT, ustekinumab in PSUMMIT1/PSUMMIT-2 trial, with apremilast $30 \mathrm{mg}$ only in PALACE 3 , with ixekizumab and adalimumab in SPIRIT-P1 (post hoc analysis).

For secukinumab, results are different: McInnes et al. (FUTURE 2) found no sig nificant efficacy with $47 \%$ of dactylitis resolution at 24 weeks for secukinumab vs $11 \%$ for placebo $(\mathrm{p}=0.9195)$. At the opposite, Kavanaugh et al. (FUTURE 2$)$ demonstrated secukinumab efficacy on anti-TNF-naïve (300 mg and $150 \mathrm{mg}$ dosages) and anti-TNF-exposed patients (only $300 \mathrm{mg}$ ).

For Mc Innes et al., clazakizumab permitted great decreases in the mean number of dactylitis from baseline to weeks 16 and 24 but no statistical data are available in the report. Similarly, in a recent publication, promising results were found for tofacitinib and abatacept, but no statistical data are available.

At the opposite, no significant efficacy was demonstrated in a randomised controlled trial with brodalumab.

Calculating of effect size was possible and available only in one study: secukinumab's effect size was 4.35 in McInnes study (FUTURE 2). Calculation of Odds Ratio (with of residual dactylitis between treatment and placebo groups was possible on part of studies with significant results for clazakizumab (200 mg dosing) and secukinumab in patients TNF exposed (figure 1).
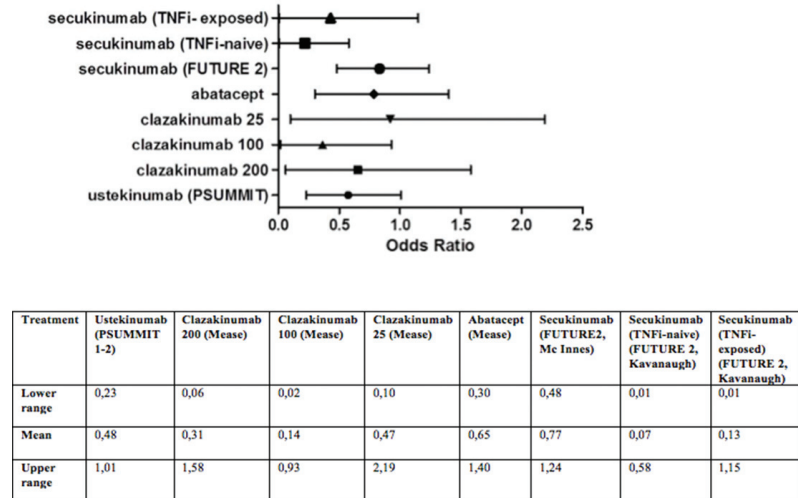

Abstract AB0937 - Figure 1. Odds Ratio for residual dactylitis in treatment/placebo groups

Conclusions: Dactylitis was always used as secondary outcome criteria with heterogeneous results. So conclusions need to be cautious. This invalidating clinica manifestation need to be evaluated as a primary outcome in the future.

Disclosure of Interest: None declared

DOI: 10.1136/annrheumdis-2018-eular.2521 